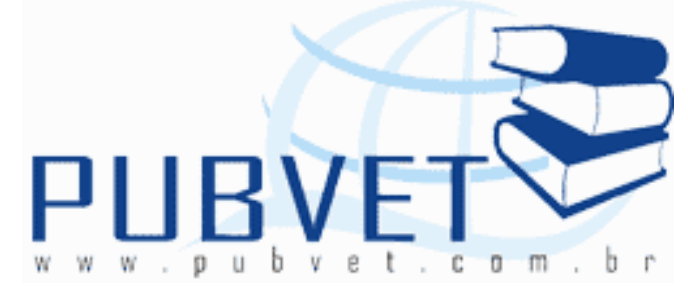

PUBVET, Publicações em Medicina Veterinária e Zootecnia.

\title{
Análise da qualidade de vida dos pequenos produtores de leite no Município de Grupiara, MG
}

\section{Inês dos Reis Leite ${ }^{1}$ e Cláudio Costa ${ }^{2}$}

${ }^{1}$ Administradora de empresas.

${ }^{2}$ Professor titular da FUCAMP - Monte Carmelo - MG.

\section{Resumo}

A atividade leiteira é importante para o agricultor familiar na complementação da sua renda. Este estudo tem como objetivo analisar a qualidade de vida do pequeno produtor de leite no município de Grupiara- MG. Foi realizada uma pesquisa exploratória, com aplicação de questionários para 25 produtores de leite com produção de até 6.000 litros mês. Os resultados indicam que $60 \%$ dos produtores estão com idade acima de 56 anos e nenhum apresenta idade inferior a 25 anos, 68\% estão na atividade a mais de 20 anos. Na análise da expectativa do produtor em relação à produção, $40 \%$ se mostram otimistas e pretende aumentar a produção, $88 \%$ dos produtores residem na zona rural, a participação dos filhos na atividade é de 32\%. No levantamento das dificuldades enfrentadas e a satisfação do produtor, $52 \%$ diz que o apoio financeiro é muito pequeno e $48 \%$ está no elevado custo de produção, mesmo com diversas dificuldades $92 \%$ estão satisfeitos com atividade e $76 \%$ se veem em outra atividade produtiva sendo a agricultura segunda opção. Portanto, o trabalho mostra uma população do campo envelhecida e satisfeita com a 
LEITE, I.R. e COSTA, C. Análise da qualidade de vida dos pequenos produtores de leite no Município de Grupiara, MG. PUBVET, Londrina, V. 7, N. 13, Ed. 236, Art. 1556, Julho, 2013.

atividade leiteira, pois apresentam condição de vida adequada e bens materiais necessários para suas necessidades.

Palavras-chave: Agricultura familiar; Agronegócio; Atividade leiteira.

\title{
Life quality analysis of small milk producers from the town of Grupiara, MG
}

\begin{abstract}
The dairy business is important to the agricultural family workers to complement their income. This study has the target analyze the life quality of small milk producer in Grupiara, a municipality in Minas Gerais State. We conducted an exploratory survey, with the aid of questionnaires to 25 milk producers that produce up to 6,000 liters a month. The results indicate that $60 \%$ of the farmers are over 56 years old and none of them are younger than $25 ; 68 \%$ have been in the dairy business for over 20 years now. As to their expectation for the production, $40 \%$ are optimistic and have plans to increase production. $88 \%$ of these farmers living in rural areas, and have their kids help them in farming activities in $32 \%$ of the cases. The survey showed the difficulties producers have and how satisfied they are: $52 \%$ said that financial aid is too little, and $48 \%$ blame the high cost of production for their problems; still, $92 \%$ are satisfied despite all difficulties, and $76 \%$ picture themselves working in a different activity, making agriculture come second. Therefore, the paper shows an aged working population, yet satisfied with the dairy business, for they have adequate living conditions and own the goods necessary for their needs.
\end{abstract}

Keywords: Family agriculture; Agribusiness; Dairy activity.

\section{INTRODUÇÃO}

O agronegócio tem sua importância econômica e social no mercado brasileiro por estar diretamente ligado à geração de emprego e renda nos municípios. O Produto Interno Bruto (PIB) do agronegócio, no ano de 2011, 
atingiu $\mathrm{R} \$ 46,6$ bilhões no terceiro trimestre. A agricultura alcançou 70,4\% do PIB do setor, e a pecuária 29,6\% (TOLOI; REINERT, 2011). Nos dias atuais, o complexo agroindustrial brasileiro tem posição de destaque no mercado nacional e internacional, sendo responsável por 30\% do PIB nacional. Comparado com outros países o Brasil apresenta perspectivas favoráveis no setor agropecuário, por apresentar áreas amplas, solo, relevo e condições climáticas apropriadas ao desenvolvimento do mesmo (PEREIRA; MANGUALDE, 2011).

A produção de leite, segundo Nero, Viçosa e Pereira (2009), tornou-se uma atividade economicamente importante para o país, praticada principalmente por pequenos produtores. Esta atividade produtiva tem contribuído para o setor agropecuário, que ao estabelecer mais renda e empregos aos produtores, tem por consequência sua estabilidade no campo (CAMPOS; PIACENTI, 2007). A demanda de leite cresceu de 18 bilhões de litros para 20 bilhões no ano de 2012, fato que aumentou os investimentos nesse setor, principalmente na compra de ordenhadeiras mecânicas (SILVA; MOREIRA; PERES, 2012).

O crescimento social e econômico da agricultura familiar tornou relevante para o agronegócio brasileiro, devido às oportunidades de emprego e a contribuição para economia local. Ao desempenho dessa atividade agrega-se de sentimento, isso se deve ao fato de ser realizado dentro do ambiente familiar (LOURENZANI, 2006). A agricultura familiar tem como sinônimo, "baixa produção", sendo uma visão antecipada do desenvolvimento econômico da atividade. Pensar que o produtor vive em um ambiente escasso de recursos é desconhecer sua participação econômica no mercado nacional (HANASHIRO et al., 2011).

O termo qualidade de vida, segundo Souza, Silva e Lucena (2009), possui uma ampla definição, em relação às experiências do indivíduo, sendo essas emocionais com o seu trabalho, em momentos de transformações na sociedade e na tecnologia, de maneira contínua e acelerada. O bem estar da pessoa reflete as consequências que o ambiente do trabalho lhe trouxe, sendo 
voltada para resultados positivos na produtividade. O desenvolvimento rural proporciona alternativa a qualidade de vida do agricultor familiar, devido sua aproximação à tecnologia, ao avanço econômico e a confiança financeira, sem avaliar os aspectos culturais e ambientais (BARROZO et al., 2010).

$\mathrm{O}$ aumento da renda familiar impulsionou um maior consumo de leite nos últimos anos, refletindo em uma expansão de 9,85\% da atividade, mas consequentemente os altos custos da produção diminuíram a renda desse produtor (BARROS; SILVA; FACHINELLO, 2011). Com vistas neste cenário o objetivo desse trabalho foi analisar a qualidade de vida dos pequenos produtores de leite no município de Grupiara - MG.

\section{IMPORTÂNCIA DA AGRICULTURA FAMILIAR NO AGRONEGÓCIO BRASILEIRO}

A definição do termo agronegócio teve sua origem na Universidade de Harvard por meio de uma ampla definição das atividades agropecuárias pelo professor John Davis (ANDRADE; GONTIJO; FRANÇA, 2011). O termo, segundo Toloi e Reinert (2011), equivale às atividades ligadas ao campo, executadas na pecuária e na agricultura. A descrição procede do conceito da agricultura por explicar os processos do setor primário desde a preparação do solo à colheita. Atualmente, essa explicação não consegue completar a abrangência do setor, pelo fato da dependência de serviços mecânicos como máquinas agrícolas, não sendo mais somente o homem na execução das tarefas rurais. O conceito de agribusiness surge para descrever uma nova realidade agrícola. A interpretação dessa nova realidade exalta várias dimensões comerciais para os produtos agrícolas.

Os diversos segmentos do agronegócio, primários ou secundários empregam atualmente 30 milhões de pessoas ( RIBEIRO FILHO, 2011). O Brasil além de produzir a maior parte de alimentos para o consumo do país, exporta, tornando o maior exportador mundial de grãos, óleo, farelo, carnes, açúcar. Assim classifica-se o país na quinta potência do agronegócio mundial. As condições climáticas, o solo, a modernização das técnicas de produção são 
fatores que explicam o ótimo desempenho da atividade agropecuária. A aptidão empreendedora dos produtores brasileiros tem um elevado grau de contribuição no resultado positivo do agronegócio, devido à capacidade de superação e adaptação às novas tecnologias (RIBEIRO FILHO, 2011).

Os investimentos em novas tecnologias na parte da produção agrícola e pecuária, segundo Novaes et al. (2009), tornam responsáveis pelo aumento da produtividade no setor do agronegócio. A Empresa Brasileira de Pesquisa Agropecuária (EMBRAPA) desenvolve pesquisas em várias regiões para ampliação tecnológica e intensificação da produção em todo país. Por conseqüência da inclusão da tecnologia no meio rural o setor precisa de mão de obra qualificada.

A agricultura familiar possui diversidades em termo de pluralidade de meios, utilização de recursos de geração de emprego e renda (HANASHIRO et al; 2011). A definição de agricultura familiar, segundo Machado e Silva (2004), torna complexa a partir da visão econômica, social e cultural do pequeno agricultor. O trabalho do produtor rural e as tarefas realizadas têm que ser superiores ao trabalho contratado para se definir como trabalho familiar. Um grande número de produtores brasileiros está inserido em pequenas propriedades que podem ser próprias ou arrendadas. São pessoas com baixo grau de ensino que produzem diversos produtos para aumentar sua renda, dispondo de mão-de-obra familiar e oportunidades ambientais. A agricultura familiar representa $30 \%$ da produção mundial e grande parte da produção de alimentos básicos presentes na dieta brasileira equivalem a $60 \%$ da produtividade do agricultor familiar (ANDRADE; GONTIJO; FRANÇA, 2011).

Os pequenos produtores, segundo Hofer et al. (2011), enfrentam obstáculos econômicos e ambientais para viver no campo. Os fatores econômicos são definidos pela variação dos preços dos produtos agropecuários e pela demanda e oferta. As condições climáticas afetam direta e indiretamente o produtor com geadas, estiagens e tempestades. Os desafios no meio rural são intensos, mas a atividade desenvolvida por pequenos 
empreendedores rurais passa a ser importante economicamente para o país, em função da produção de alimentos para o consumo interno.

O mundo atualmente abriga 7 bilhões de indivíduos, consequentemente o setor agrícola e da pecuária tem que dobrar a produção para alimentar essa demanda. O Brasil também tem uma função desafiadora, precisa alimentar os 30 milhões de pessoas que estão consumindo mais, pelo fato de terem saído da linha da pobreza. O pequeno produtor está inserido nessa missão para produzir e servir a população e o agronegócio brasileiro (RIBEIRO FILHO, 2011).

O pequeno produtor possui necessidade de utilizar ferramentas gerenciais e ter conhecimentos contábeis para uma melhor administração de seus recursos, mas dificuldades a adequação dessas ferramentas de gestão são encontradas na realidade familiar (ANDRADE; GONTIJO; FRANÇA, 2011). As necessidades de um agricultor vão além da produção, o mesmo e sua família são consumidores que possuem necessidades básicas como alimentação, vestuário, materiais escolares das crianças. Como pessoa, o agricultor precisa ter uma renda mensal para sua manutenção. No início, a atividade agrícola apresenta custos, tendo retorno muitas vezes somente no final do ciclo, com isso o agricultor carece desenvolver outros meios para complementar sua renda (ALVES et al; 2011).

O pequeno agricultor pode complementar sua renda com a produção de leite, sendo uma atividade de grande importância para esse setor. A atividade leiteira é extremamente explorada pelo agricultor familiar brasileiro. Vários são os fatores que justificam a entrada nesse mercado, como o fato do leite ser um produto tanto para consumo interno como para comercialização, a mão-deobra ser mais familiar do que contratada, o uso de terras pode ser particulares ou de terceiros, renda mensal garantida. No entanto, as modificações no ciclo produtivo do leite fazem com que o pequeno produtor se especialize para acompanhar o mercado (SOUZA; WAQUIL, 2008).

Possuir uma noção ou conhecimento da atividade se tornou fundamental para o produtor se direcionar e projetar diante do mercado, e 
assim adaptar e tomar decisões frente a obstáculos existentes na atividade (CAMPOS; PIACENTI, 2007). A atividade leiteira no Brasil, segundo Silva, Moreira e Peres (2012), além de contribuir para a formação do PIB, tem grande importância e tradição para a população brasileira ao gerar emprego e renda.

A região Sudeste é a grande responsável pela produção nacional de leite, em seguida aparece região Sul (FISCHER et al., 2010). O mercado leiteiro está cada vez mais competitivo, segundo Santos, Souza e Braga Filho (2011), e por esse motivo o produtor tem que procurar alternativas que the proporcione um produto de qualidade, a baixo custo, e que garanta obtenção de lucro. Devido às transformações na cadeia produtiva do leite, o pequeno produtor tem que criar estratégias para se desenvolver e permanecer na atividade (FISCHER et al., 2010). O agrupamento desses produtores em forma de associação ou cooperativa segundo Chaddad (2005) seria uma forma de unir forças e atenuar as dificuldades presente na atividade e aumentar o poder de barganha.

Uma alternativa para o pequeno produtor de leite se fortalecer no mercado, é o associativismo ou cooperativismo, estrutura que organiza a classe com os mesmos interesses. As cooperativas obtêm vantagens que são benéficas ao produtor na redução de impostos que diminui no custo do produto final (SOUZA; WAQUIL, 2008).

Vários fatores dificultam a permanência do pequeno agricultor na atividade leiteira, segundo Ferrari et al. (2005), como o transporte do produto, a forma de pagamentos, produtores mais capitalizados, a baixa remuneração da atividade devido a pequena produção. A utilização correta dos recursos disponíveis determina o nível de eficiência do produtor em alcançar bons resultados (PINHEIRO; ALTAFIN, 2007).

O aperfeiçoamento da atividade leiteira, segundo Souza e Alves (2010), ajuda ao produtor diminuir a variação que as estações trazem a produção. Assim o produtor com uma renda estável lucra com a elevação do preço em determinados períodos. A pecuária leiteira se divide em duas produções, 
período de seca e de chuva. Produtores com o mesmo número de vacas produzem diferentes quantidades de leite, isso se explica pela eficiência de cada produtor em utilizar seus recursos (PINHEIRO; ALTAFIN, 2007). A ausência de gerenciamento, segundo Lourenzani (2006), tornou um grande obstáculo no cotidiano de muitos produtores familiares que não possuem capacitação para gerenciar seus recursos.

\section{QUALIDADE DE VIDA NO CAMPO}

O assunto qualidade de vida por ser um termo amplo possui sua definição ainda em construção. Explicar claramente as variáveis necessárias que um indivíduo precisa para encontrar seu conforto torna difícil, principalmente devido à extensão que esse tema vem apresentando ao longo dos tempos (BARROZO et al.,2010). A satisfação desse pequeno produtor tem sido relacionada com o meio onde vive e as dificuldades a serem superadas. $O$ ambiente de trabalho tem que ser adequado para o produtor na busca de aumentar sua eficiência e produtividade (RIBEIRO; CAMPOS, 2009).

$O$ agricultor familiar enfrenta dificuldades em seu cotidiano, mas a adaptação de seus recursos a sua realidade pode the trazer êxito (LEITE, 2005). Ainda existem pequenos produtores que desconhecem as transformações mercadológicas, sendo sua atividade o único meio de atuação, suas necessidades consumidoras e pessoais são desprezadas pelo fato do agricultor romper a ligação da sua vida profissional com os outros elementos da cadeia produtiva (LOURENZANI, 2006).

O indivíduo para sua sobrevivência, segundo Ribeiro e Campos (2009), trabalha não por escolha e sim por necessidade. O trabalho torna importante para a população na busca de recursos para a sua alimentação, vestuário e lazer. A qualidade de vida no trabalho apresenta a compreensão da maneira correta de executar o trabalho para que possa refletir positivamente na vida do trabalhador de forma profissional e pessoal.

Com a ampliação da agricultura familiar no meio rural, o pequeno produtor busca intensamente melhorar suas condições de vida. Essa busca 
está relacionada com as habilidades em executar atividades com muito ou pouco recurso. Nos dias atuais o conceito de qualidade de vida abrange dois ângulos, um direcionado a vida material e sentimental do ser humano e o outro lado focam o desenvolvimento social da humanidade (BARROZO et al., 2010). O indivíduo procura meios, segundo Ribeiro e Campos (2009), para diminuir seus esforços na realização das suas tarefas. O mundo rural agrega valores culturais de ordem camponesa ligada à natureza, ao trabalho manual e a família. A diferença entre a sociedade rural com a urbana está na cultura de cada uma. A reflexão da realidade dessa cultura auxilia no crescimento da economia e da sociedade e na melhora da qualidade de vida no campo (BARROZO et al., 2010).

O país encontra um grande número de pessoas que não conseguem suprir suas necessidades básicas como uma refeição completa, casa própria, educação e saúde. Esses indivíduos estão localizados na zona urbana e rural. Desta forma, sem bens materiais e condições adequadas as outras necessidades não são alcançadas (SILVA; SANTOS; SANTOS, 2011). A qualidade de vida da pessoa que vive na zona rural, segundo Barrozo et al. (2010), tem que ser analisada pela particularidade de seu meio, seu contato com a natureza, suas relações pessoais e o trabalho com a agricultura. A preservação do meio ambiente entra em atrito com a nova forma de produzir alimentos saudáveis. Por esse motivo uma nova visão foi formada para a realidade do campo. Dentro dessa possibilidade, o ambiente rural torna uma área de promoção à qualidade de vida para a população rural e urbana. Mas não são todas as áreas rurais que estão nesse nível, muitos agricultores não têm como prioridade a preservação do meio ambiente.

O desenvolvimento rural vai muito além da produção e tecnologia, nele há uma ligação direta de princípios da ética, do ambiente e da humanidade. Havendo uma cooperação mútua entre os seres. O agricultor familiar respeita o desenvolvimento do meio rural e teoria da igualdade social, mas não significa que ele vai se adaptar às novas tecnologias presentes em seu meio de atuação (HANASHIRO et al., 2011). Ainda existem produtores que executam suas 
tarefas de forma rudimentar, ignorando equipamentos tecnológicos que poderiam auxiliar e aumentar sua produtividade. Com transformações constantes no meio rural, pequenos agricultores buscam mesmo com pouco capital investir em melhores condições de realizar seu trabalho, proporcionando um aumento na sua qualidade de vida (COSTA et al.,2011).

\section{METODOLOGIA}

O trabalho foi conduzido no município de Grupiara - MG, que tem 1.373 habitantes sendo que 200 vivem na zona rural (IBGE, 2010). Para análise foram selecionados 25 produtores, estes com produção inferior ou igual a 6.000 litros por mês, a listagem foi fornecida pelo escritório local da Empresa de Assistência e Extensão Rural (EMATER). O questionário foi modificado com base no estudo de Brito (2006) e apresenta 17 questões. As questões 1, 2, 3, $5,6,10$ e 16 retratam condições sócio econômica do entrevistado. As perguntas 4, 8, 9, e 12 mostram as condições de infra estrutura da habitação e quais bens de consumo e duráveis o produtor possui. Nas questões 11,13 e 14 a abordagem está na satisfação e expectativa de futuro pela atividade e a participação familiar. As perguntas 7, 15 e 17 abordam as dificuldades enfrentadas pelo produtor, sua satisfação pelo que faz e se tem outra opção de atividades produtiva. Sendo que as questões $4,6,7,9,12,14$ e 16 o produtor respondeu mais de uma alternativa. A pesquisa foi realizada por meio de visita nas residências dos produtores pela autora, o questionário foi respondido por meio de leitura da própria autora, que por sua vez, assinalava as alternativas apontadas pelo produtor. Assim os dados foram tabulados e analisados.

\section{RESULTADOS E DISCUSSÃO}

Observou-se na tabela 1 , que $60 \%$ dos produtores estavam com idade acima de 56 anos e nenhum entrevistado apresenta idade inferior a 25 anos. Uns dos fatores que faz a atividade não ser atrativa e até mesmo desmotivadora para os jovens, é o fato do trabalho ser contínuo de domingo a 
domingo, sem feriado e nenhum descanso semanal. A continuação da atividade rural pelos jovens, segundo Rincon e Hennemann (2009), sucede pela importância do desenvolvimento sustentável, pelo fato que o meio rural apresenta uma população envelhecida, com pouca preparação. O investimento nos jovens na sua qualificação no campo é um método de modificação social que tem como objetivo equilibrar a sociedade rural e urbana, para melhorar a qualidade de vida e evitar o êxodo rural para as cidades.

Ao verificar o tempo em que esses produtores estão na atividade, $69 \%$ estão com mais de 20 anos. Dados que comprova a dependência do produtor pela atividade, por ele estar muito tempo na produção de leite, acaba criando uma ligação afetiva no que faz.

No estudo de Hofer et al. (2011) no município de Marechal Cândido no estado do Paraná a faixa etária média dos entrevistados foi de 49 anos e $87,76 \%$ disseram que atuam a mais de 20 anos na atividade rural. Outra realidade próxima foi encontrada no município de Boa Esperança - MG na Comunidade de Mato Seco no estudo de Melo e Reis (2007) em relação à faixa etária dos entrevistados $62,5 \%$ estão entre 46 a 55 anos e no mesmo estudo na Comunidade de Machados 43,8\% estão acima de 56 anos. Dados que comprovam uma população do campo envelhecida em diferentes partes do país.

Em 32\% das propriedades, os produtores possuem ensino primário completo. Os produtores alegam que para atividade não precisam do ensino superior para realização das tarefas, e a outra parte confirma que a atividade ocupa todo o seu tempo e com isso perderam o interesse de continuar os estudos. Na Comunidade do Paicel no estudo de Melo e Reis (2007) 71,4\% cursaram o ensino fundamental, dados que confirmam que a população do campo é menos instruída, o motivo do nível de ensino ser tão baixo nessa atividade, segundo Corá, Begnini e Rech (2011) se deve às dificuldades enfrentadas e a atividade exigir muito tempo do produtor. 
Tabela 1- Levantamento do perfil sócio-econômico do pequeno produtor de leite no município de Grupiara- MG.

\begin{tabular}{|c|c|c|}
\hline Variáveis & $\mathbf{n}$ & Frequência (\%) \\
\hline \multicolumn{3}{|l|}{ 1- Idade dos produtores } \\
\hline $1-18$ a 25 anos & 00 & $0 \%$ \\
\hline 2- 26 a 35 anos & 01 & $4 \%$ \\
\hline 3- 36 a 45 anos & 02 & $8 \%$ \\
\hline 4- 46 a 55 anos & 07 & $28 \%$ \\
\hline 5- 56 a 65 anos & 08 & $32 \%$ \\
\hline 6- mais de 66 anos & 07 & $28 \%$ \\
\hline \multicolumn{3}{|c|}{ 2- Há quanto tempo está na atividade } \\
\hline 1- Menos de 05 anos & 00 & $0 \%$ \\
\hline 2- Entre 06 a 10 anos & 02 & $8 \%$ \\
\hline 3- Entre 11 e 15 anos & 00 & $0 \%$ \\
\hline 4- Entre 16 e 20 anos & 06 & $24 \%$ \\
\hline 5- Mais de 20 anos & 17 & $68 \%$ \\
\hline \multicolumn{3}{|l|}{ 3- Alfabetização do respondente } \\
\hline 1- Não sabe ler nem escrever & 01 & $4 \%$ \\
\hline 2- Sabe ler/escrever/grau de ensino & 04 & $16 \%$ \\
\hline 3- Ensino primário completo & 08 & $32 \%$ \\
\hline 4- Ensino secundário & 04 & $16 \%$ \\
\hline 5- Ensino médio/profissional & 06 & $24 \%$ \\
\hline 6- Ensino superior incompleto & 02 & $8 \%$ \\
\hline 7- Ensino superior completo & 00 & $0 \%$ \\
\hline \multicolumn{3}{|c|}{ 5- É proprietário da parcela que produz? } \\
\hline $1-\operatorname{Sim}$ & 23 & $92 \%$ \\
\hline 2- Não & 01 & $4 \%$ \\
\hline 3- Outro membro familiar & 01 & $4 \%$ \\
\hline \multicolumn{3}{|l|}{ 6- Se é proprietário, como adquiriu? } \\
\hline 1- Herança & 21 & $84 \%$ \\
\hline 2 - Compra & 07 & $28 \%$ \\
\hline 3 - Doação & 00 & $0 \%$ \\
\hline \multicolumn{3}{|c|}{ 10- Mão de obra utilizada na propriedade: } \\
\hline 1- diarista & 15 & $60 \%$ \\
\hline 2- permanente & 10 & $40 \%$ \\
\hline \multicolumn{3}{|l|}{ 16- Qual a origem de sua renda? } \\
\hline 1-Somente a produção de leite & 7 & $28 \%$ \\
\hline 2-Trabalha para terceiros & 1 & $4 \%$ \\
\hline 3- Exerce outra profissão & 7 & $28 \%$ \\
\hline 4- Aposentado & 0 & $40 \%$ \\
\hline
\end{tabular}


De acordo com os produtores, $92 \%$ são proprietários das suas terras, sendo $84 \%$ adquiridas por herança. Portanto, muitos desses produtores estão na atividade para continuar o que seus pais e avôs ensinaram, muitos veem na atividade leiteira uma tradição familiar. No estado de São Paulo no estudo de Hanashiro et al. (2011) 82,5\% são proprietários de suas terras e a outra parte trabalha em terras arrendadas. No estudo de Hofer et al. (2011), 21,15\% dos entrevistados teve seu patrimônio oriundo de herança familiar, 48,07\% receberam parte do patrimônio através de herança e aumentaram o mesmo com a renda da própria atividade. A transmissão do saber das atividades rurais para gerações futuras, segundo Cintra e Bazotti (2012), está comprometida pela diminuição da participação dos filhos na agricultura familiar e por habitarem no meio urbano.

$\mathrm{Na}$ realização das tarefas somente $40 \%$ trabalham de forma permanente, $60 \%$ necessitam de mão de obra diária de terceiros. 0 estudo de Silva Neto e Basso (2005), no Rio Grande do Sul, mostra que para o desenvolvimento da produção de leite o trabalho assalariado não é viável, pois essa atividade necessita de trabalho permanente que muitas das vezes ultrapassa a jornada normal de trabalho.

A origem da renda do pequeno produtor mostra que $40 \%$ são aposentados, tendo a produção de leite um complemento a sua renda, $28 \%$ vivem apenas com a atividade leiteira.

No estudo da tabela 2 , a análise mostra que $80 \%$ dos produtores possuem água encanada, $100 \%$ possuem eletricidade e $92 \%$ possuem banheiro e $84 \%$ tem fossa sanitária na propriedade. Apesar das dificuldades financeiras que o produtor enfrenta $92 \%$ possuem veículo próprio, $69,56 \%$ dos veículos estão entre os anos de 2000 a 2011, esses dados mostram que o pequeno produtor investe em bens de consumo durável e isso mostra que a atividade propõe uma satisfação e conforto ao pequeno produtor. No estudo de Barrozo et al. (2010) no assentamento Santa Bárbara II no Ceará, o autor constatou que a possibilidade de consumir uma maior quantidade e com uma diversidade maior de bens duráveis, a satisfação dos entrevistados aumentam. 
Tabela 2. Levantamento da infra-estrutura física, de bens duráveis adquiridos e equipamentos utilizados pelos pequenos produtores de leite no município de Grupiara-MG.

\begin{tabular}{|c|c|c|}
\hline Variáveis & $\mathbf{n}$ & Frequência(\%) \\
\hline \multicolumn{3}{|c|}{ 4- Infraestrutura disponível na habitação } \\
\hline 1- Água encanada & 20 & $80,00 \%$ \\
\hline 2- Eletricidade & 25 & $100,00 \%$ \\
\hline 3- Fossa sanitária & 21 & $84,00 \%$ \\
\hline 4- Banheiro & 23 & $92,00 \%$ \\
\hline 5- Nenhum & 0 & $0 \%$ \\
\hline \multicolumn{3}{|l|}{ 6- Outra } \\
\hline \multicolumn{3}{|l|}{ 8- Possui veículo próprio? } \\
\hline \multicolumn{3}{|c|}{ Se sim, qual ano de fabricação? } \\
\hline A- Sim & 23 & $92 \%$ \\
\hline B- Não & 2 & $8 \%$ \\
\hline $1-<1990$ & 3 & $13,04 \%$ \\
\hline 2- 1990 a 1995 & 2 & $8,70 \%$ \\
\hline 3- 1995 a 2000 & 2 & $8,70 \%$ \\
\hline 4- 2000 a 2005 & 5 & $21,74 \%$ \\
\hline 5- 2005 a 2010 & 8 & $34,78 \%$ \\
\hline 6- > 2011 & 3 & $13,04 \%$ \\
\hline \multicolumn{3}{|c|}{ 9- Quais os eletrodomésticos/eletrônicos possui? } \\
\hline 1- liquidificador & 23 & $92,00 \%$ \\
\hline 2- batedeira & 13 & $52,00 \%$ \\
\hline 3- microondas & 7 & $28,00 \%$ \\
\hline 4- geladeira & 24 & $96,00 \%$ \\
\hline 5- televisão & 23 & $92,00 \%$ \\
\hline 6- computador & 2 & $8,00 \%$ \\
\hline 7- dvd/vídeo-cassete & 9 & $36,00 \%$ \\
\hline 8- aparelho de som & 17 & $68,00 \%$ \\
\hline 9- notebook & 2 & $8,00 \%$ \\
\hline 10- celular & 21 & $84,00 \%$ \\
\hline 11- máquina de lavar roupas & 23 & $92,00 \%$ \\
\hline \multicolumn{3}{|c|}{ 12- Quais os tipos de equipamentos usados na atividade } \\
\hline 1-trator & 8 & $32,00 \%$ \\
\hline 2-ordenhadeira & 6 & $24,00 \%$ \\
\hline 3-tração animal (carroça) & 13 & $52,00 \%$ \\
\hline 4-botijão criogênico de sêmen & 0 & $0 \%$ \\
\hline
\end{tabular}


$\mathrm{Na}$ interpretação dos dados colhidos os produtores possuem eletrodomésticos necessários para sua vida doméstica, na busca pelo conforto no meio rural 96\% possuem geladeira, 92\% possuem televisão, $84 \%$ possuem telefone celular e $92 \%$ possuem máquina de lavar, mas o importante dessa amostra é que o pequeno produtor está excluído da era digital apenas $8 \%$ possui computador. Esse computador na zonal rural seria uma ferramenta de imensa utilidade para o produtor em termo de gestão de recursos e informações. No estado do Paraná no estudo de Hofer et al. (2011) a realidade é outra $40 \%$ possuem computadores e acesso a internet em suas propriedades. De acordo com Lourenzani (2006), o produtor fica ligado apenas na sua atividade, sem perceber que fora da fazenda existe um mercado em movimento, e nesse mercado ele é consumidor e as tecnologias que ele não adquire, atrasa todo o processo produtivo.

Ainda $52 \%$ desses produtores necessitam do uso da carroça para realização das suas atividades. Apenas 24\% possuem ordenhadeira mecânica, devido à quantidade de leite produzida, os tratores usados na propriedade são de terceiros ou da associação e apenas 32\% utilizam essa ferramenta na atividade. No estudo de Hanashiro et al.(2011) no estado de São Paulo, o autor confronta a idéia que diz que o produtor precise da utilização de tratores, ou seja o produtor tem que usar a tecnologia que ele precise seja ela simplificada, como o implementos de tração animal ( carroça).

Verificando a tabela 3, a expectativa do produtor em aumentar a produção nos próximos 10 anos equivale a $40 \%$ mostrando que o produtor enfrenta as dificuldades com otimismo, mas $24 \%$ pretende parar. Essa parcela que pretende parar, afirma que a idade é o fator que mais pesa ao passar dos anos.

As participações dos filhos na produção são de apenas 32\%, pois muitos já residem e trabalham na zona urbana, esse índice confirma que a continuação da atividade pelos filhos é incerta. Grande parte dos produtores reside na zona rural apenas $12 \%$ moram na cidade devido à escola para os filhos e facilidade a serviços e produtos. A produção de alimentos, segundo 
Rincon e Hennemann (2009), está ficando cada vez mais nas mãos das pessoas com idade elevada, o proprietário rural tem pouca informação e não se preocupam em longo prazo, em quem vai assumir sua atividade. Precisa com urgência educar os jovens, para que a empresa rural continue a existir para gerar renda e empregos.

Tabela 3. Levantamento da expectativa em relação à permanência na atividade produtiva e a participação familiar do pequeno produtor de leite no município de Grupiara- MG

\begin{tabular}{|c|c|c|}
\hline Variáveis & $\mathbf{n}$ & Frequência\% \\
\hline \multirow{2}{*}{\multicolumn{3}{|c|}{$\begin{array}{l}\text { 13- Quais as expectativas para a } \\
\text { produção de leite nos próximos } 10 \text { anos? }\end{array}$}} \\
\hline & & \\
\hline 1-Manter & 6 & $24 \%$ \\
\hline 2-Aumentar & 10 & $40 \%$ \\
\hline 3-Diminuir & 3 & $12 \%$ \\
\hline 4-Parar & 6 & $24 \%$ \\
\hline \multicolumn{3}{|c|}{ 14- Qual a participação da família na atividade? } \\
\hline 1-Pais & 16 & $64 \%$ \\
\hline 2-Filhos & 8 & $32 \%$ \\
\hline 3-Irmãos & 3 & $12 \%$ \\
\hline 4-Genros & 2 & $8 \%$ \\
\hline 5-Netos & 0 & $0 \%$ \\
\hline \multicolumn{3}{|l|}{ 11- Onde reside? } \\
\hline 1-Zona rural & 22 & $88 \%$ \\
\hline 2-Zona urbana & 3 & $12 \%$ \\
\hline \multicolumn{3}{|l|}{ 11.1-Se mora na cidade, qual motivo? } \\
\hline 1-Conforto & 0 & 0 \\
\hline 2-Filhos na escola & 1 & $20 \%$ \\
\hline 3-Facilidade de negociação & 1 & $20 \%$ \\
\hline 4-Facilidade de acesso a serviços e produtos & 3 & $60 \%$ \\
\hline
\end{tabular}


Percebem-se, pelos dados apresentados na Tabela 4, que são várias as dificuldades que o pequeno produtor enfrenta, mas 52\% representam falta de apoio financeiro tanto do município quanto da União, o elevado custo da produção $48 \%$ compromete seriamente a atividade e o lucro do produtor. No trabalho de Silva Neto e Basso (2005) no Rio Grande do Sul as dificuldades estão relacionadas aos aspectos financeiros, a atividade em visão técnica se torna viável economicamente, mas as melhorias pra aumentar a produção são bastante complicadas no ponto de vista financeiro. O interessante dessa questão que o produtor ainda é satisfeito com que faz com um percentual de 92\% de satisfação. De acordo com Silva, Santos e Santos (2011) se o indivíduo tem condições de habitação adequadas e bens materiais suas necessidades são alcançadas e se mostram satisfeitos.

O mercado de leite oscila muito nas variáveis como preço - custo, por esse motivo $76 \%$ dos produtores se veem em outra atividade produtiva, sendo a agricultura uma nova opção para o produtor com 47,36\%. Na visão de Andrade, Gontijo e França (2011) em um trabalho realizado na Fazenda Paraíso no município de Carmo do Paranaíba- MG a diversificação de atividades na propriedade reduz riscos e incertezas no empreendimento rural e gera lucro ao produtor, no que se refere a crise econômica em algum setor e até mesmo as condições climáticas. Várias são as dificuldades que afetam o pequeno produtor de leite, segundo Silva Neto e Basso (2005), eles continuam otimistas pelo fato da atividade contribuir de maneira econômica e social no equilíbrio da sociedade.

A qualidade de vida do pequeno produtor de leite vai além de ter condições adequadas de vida e bens de consumo duráveis, o pequeno produtor mostra que na realização da atividade leiteira mesmo com poucos recursos disponíveis suas habilidades e experiência ajuda no êxito do resultado, trazendo satisfação profissional e pessoal. 
Tabela 4. Levantamento das dificuldades enfrentadas pelo produtor, a satisfação pela execução da atividade e a visão de pequenos produtores de leite em outra atividade produtiva no município de Grupiara- MG.

\begin{tabular}{lcc}
\hline Variáveis & n & Frequência\% \\
\hline 7- Indique que tipo de dificuldades enfrentadas & & \\
1- Falta de apoio financeiro & 13 & $52,00 \%$ \\
2- Reduzido o no de trabalhadores & 4 & $16,00 \%$ \\
3- Distância dos mercados & 2 & $8,00 \%$ \\
4- Falta de empregados & 0 & $0 \%$ \\
5- Falta de água & 0 & $0 \%$ \\
6- Avarias nas máquinas & 1 & $4,00 \%$ \\
7- Elevado custo da produção & 12 & $48,00 \%$ \\
\hline 15- Você está satisfeito com o que faz & & \\
Sim & 23 & $92 \%$ \\
Não & 2 & $8 \%$ \\
\hline 17- Você se vê em outra atividade produtiva? & & \\
A-Sim & 19 & $76 \%$ \\
B-Não & 6 & $24 \%$ \\
1-gado de corte & 7 & $36,85 \%$ \\
2-agricultura & 9 & $47,36 \%$ \\
3-eucalipto & 3 & $0 \%$ \\
4-outra & $39 \%$ \\
\hline
\end{tabular}

\section{CONCLUSÃO}

Os pequenos produtores de leite do município de Grupiara - MG estão satisfeitos com a atividade exercida, através dela retiram seu sustento, adquirem bens para seu conforto que proporcionam uma qualidade de vida melhor. A atividade está ameaçada pelo fato da maioria dos produtores estarem com idade elevada e daqui algum tempo esses produtores não terão força ativa para executar as tarefas diárias e seus descendentes não mostram interesse pela continuação, pelo fato de viverem e trabalharem na cidade.

Entretanto, os produtores se sentem realizados de forma profissional e pessoal, pois buscam realizar seu trabalho da melhor forma, muitas vezes com 
LEITE, I.R. e COSTA, C. Análise da qualidade de vida dos pequenos produtores de leite no Município de Grupiara, MG. PUBVET, Londrina, V. 7, N. 13, Ed. 236, Art. 1556, Julho, 2013.

poucos recursos sejam eles financeiros ou tecnológicos, mas sua experiência e o gostar do que faz, reflete positivamente na sua qualidade de vida.

\section{REFERÊNCIAS}

ALVES, V.O; VIEIRA, N.S; SILVA, T.C; FERREIRA, P.R. O associativismo na agricultura familiar dos Estados da Bahia e Minas Gerais: potencialidades e desafios frente ao programa de aquisição de alimentos (PAA), Revista Administração pública e gestão social, Viçosa, v.3, n.1, p.66-88, jan./mar. 2011.

ANDRADE, A.L.S; GONTIJO, C.M; FRANÇA, P.B. Gestão do Agronegócio familiar: estudo de caso da fazenda Paraíso. Revista Brasileira de Gestão e Engenharia. São Gotardo n.3, jan./jun. 2011.

BARROS, G.S.C.; SILVA, A.F; FACHINELLO, A.L. Agronegócio fecha $2011 \mathrm{com}$ alta de 5,73\%. Disponível em:<http: WWW.cepea.esalq.usp.br>. Acesso em: 24 abr. 2012.

BARROZO, L.C.R; LIMA, P.V.P.S; KHAN, A.S; BARQUETE, P.R.F .Projeto de assentamento e qualidade de vida dos produtores rurais: o caso do assentamento de Santa Bárbara II no Ceará. In: CONGRESSO SOBER, 48, 2010, Campo Grande. Anais....Campo Grande: CONGRESSO SOBER, 2010. p.1-21.

BRITO, B. R. Estudo Socioeconómico e Diagnóstico para Acompanhamento das Condições de Bem-Estar das Famílias da Região de Cacheu. 2006. Disponível em: $<$ www.fao.org >. Acesso em 15 set 2011.

CAMPOS, K.C.; PIACENTI, C.A. Agronegócio do leite: cenário atual e perspectivas. In: CONGRESSO SOBER, 45, 2007, Londrina. Anais....Londrina: CONGRESSO SOBER, 2007. p. 119.

CHADDAD, F.R. Estratégias competitivas para o produtor de leite. In: INTERLEITE, 5, 2005, Uberlândia. Estratégia e competitividade na Cadeia de Produção de Leite. Anais... Passo Fundo: Gráfica Editora Berthier, 2005. P.36-46.

CINTRA, A.P.U.; BAZOTTI, A. População Rural, agricultura familiar e transmissão do saber na região Sul. Caderno Instituto Paranaense de desenvolvimento econômico e social, Curitiba, V.2, n.1, p.80 - 94, jan./ jun. 2012.

CORÁ, M.B; BEGNINI, L; RECH, R. Análise sócio- econômica da associação de feirantes do município de Realeza - PR. SynergismusScyentifica, Pato Branco, v.6, n.1, 2011.

COSTA, C.K.L; LUCENA, N.M.G; TOMAZ, A.F.; MÁSCULO, F.S. Avaliação ergonômica do trabalhador rural: enfoque nos riscos laborais associados à carga física. Gestão da

Produção, Operações e Sistemas. Bauru, n.2,p.101-112, abr./jun. 2011.

FERRARI, D.L.; MELLO, M.A; TESTA, V.M; SILVESTRO, M.L. Agricultores familiares, exclusão e desafios para inserção econômica na produção de leite em Santa Catarina.

Informações Econômicas, São Paulo, v.35, n.1, jan. 2005. 
FISCHER, A.; MACHADO, N.S.; FEGER, J.E.; TREVISAN, M. Características organizacionais de empresas processadoras de leite do oeste catarinense. Análise a revista acadêmica da FACE, Porto alegre, v.21, n.2, p.114-126, jul./dez. 2010.

HANASHIRO, M.M.; MATSUURA, F.C.A.U.; LIMA, I.A.; BERIAM, L.O.S.; MADDARENA, E.F.; MINITTI, A.F.; COMITRE, V.; PIMENTEL, M.A.A., SOUZA, E.D . Transferência de tecnologia apropriadas para a agricultura familiar: uma experiência de ação integrada no Estado de São Paulo. Cadernos de Ciência \& tecnologia, Brasília, v.28, n.1, p. 51-80, jan./ abr. 2011.

HOFER, E.; PACHECO, V.; SOUZA, A.; PROTIL, R.M. A relevância do controle contábil para o desenvolvimento do agronegócio em pequenas e médias propriedades rurais. Revista de controladoria, Curitiba, v.3, n.1, p.27-42, jan./ abr. 2011.

INSTITUTO BRASILEIRO DE GEOgRAFIA E ESTATÍstICA. Cidades. Rio de Janeiro, IBGE, 2010. Disponível em : http: // WWW.ibge.br Acesso. 30 jun. 2012.

LEITE, J.L.B. Metodologia de modelagem para sistemas de produção de leite. In: CONGRESSO SOBER, 43, 2005, Ribeirão Preto. Anais... Ribeirão Preto: CONGRESSO SOBER, 2010. P.1- 15.

LOURENZANI, W.L. Capacitação gerencial de agricultores familiares: uma proposta metodológica de extensão rural. Organizações Rurais \& Agroindustriais, Lavras, v.8, n.3, p.313-322. 2006.

MACHADO, M.D.; SILVA, A.L. Distribuição de produtos provenientes da agricultura familiar: um estudo exploratório da produção de hortaliças. Revista de Administração da UFLA, Lavras, v.6, n.1, jan/jun. 2004.

MELO, A.D. S; REIS, R.P. Tanques de expansão e resfriamento de leite como alternativa de desenvolvimento regional para produtores familiares. Organizações rurais \& agroindustriais, Lavras, v.9, n.1, p.111-122. 2007.

NERO, L.A.; VIÇOSA, G.N.; PEREIRA, F.E.V. Qualidade microbiológica do leite determinada por características de produção. Ciência tecnologia de Alimentos, Campinas, v.29, n.2, p.386-390, abr./jun. 2009.

NOVAES, A.L., MOREIRA, B.C.R; OLIVEIRA, L.; TALAMINI, E.; VIANA, J.J.S . Análise dos fatores críticos de sucesso do agronegócio brasileiro. In: CONGRESSOSOBER, 48, 2009, Campo Grande. Anais.... Campo Grande: CONGRESSO SOBER, 2009. p. 1- 20.

PEREIRA, V.V.; MANGUALDE, R.M. A rotulagem ambiental no agronegócio. Revista em agronegócios e Meio Ambiente, Maringá, v.4, n.2, p.267-276, maio./ago. 2011.

PINHEIRO, M.E.F; ALTAFIN, I.G. Eficiência da produção familiar de leite em projetos de assentamento de reforma agrária: estudo multicaso. Organizações rurais \&

agroindustriais, Lavras, v.9, n.2, p.189-201. 2007.

RIBEIRO, C.A.D.; CAMPOS, L.N.M. Qualidade de vida no trabalho. Revista Tecer, Belo Horizonte, v.2, n.2, maio. 2009.

RIBEIRO FILHO, M. Resultados que alimentam o mundo. Revista de Política agrícola, Brasília, n.4, out./Nov./dez. 2011.

RINCON, A.M.C; HENNEMANN, R. A permanência da juventude rural no Distrito de Paula Pereira. Àgora, Rio de Janeiro, v.16, n.2.2009. 
SANTOS, R.A; SOUZA, T.L; BRAGA FILHO, R. Um estudo sobre a viabilidade econômica da criação de gado leiteiro numa propriedade com arrendamento rural para auxiliar na criação de gado de corte - Estudo de caso. Revista Eletrônica Saber Contábil, Ji- Paraná, v.1, n.1, p.56-73, maio./ago. 2011.

SILVA, J.C.F; SANTOS, A.L; SANTOS, C.C. Problemática ambiental dos rios urbanos: uma análise das situações de risco ambiental e qualidade de vida dos ribeirinhos do Riacho Doce da cidade de Lajedo- PE. Revista Brasileira de Geografia Física, Recife, n.3, p.520-542. 2011.

SILVA NETO, B.; BASSO, D.A. A produção de leite como estratégia de desenvolvimento para o Rio Grande do Sul. Desenvolvimento em questão. Unijuí, n.5, jan./jun. 2005.

SILVA, T.P.P.; MOREIRA, J.C.; PERES, P. Serão os carrapaticidas agrotóxicos? Implicações na saúde e na percepção de riscos de trabalhadores da pecuária leiteira. Ciências e saúde coletiva, Rio de Janeiro, v.17, n.2, p.311-325. 2012.

SOUSA, A.R.F.; SILVA, C.C.S.C.; LUCENA, L.M. Qualidade de vida no trabalho: um estudo de caso na secretária de Estado da administração e dos recursos humanos do Rio Grande do Norte. Revista científica da Escola de Gestão e negócios, Natal. 2009.

SOUZA, J.B.L; ALVES, A.F. Especialização produtiva e retornos associados para os produtores de leite. Economia \&tecnologia, Paraná, v.23,out./dez. 2010.

SOUZA, R.P.; WAQUIL, P.D. A viabilidade da agricultura familiar produtora de leite: o caso do sistema Coorlac (RS). In: CONGRESSO SOBER, 46, 2008, Rio Branco. Anais... Rio Branco: CONGRESSO SOBER, 2008. p.1-21.

TOLOI, R.C.; REINERT, J.N. Contribuição do programa de pós- graduação em agronegócio da Universidade Federal de Mato Grosso do Sul no desenvolvimento do agronegócio do Estado de Mato Grosso do Sul, Brasil. UFMS, Maringá, v.3, n.1, p.55-65, 2011. 


\section{Anexo I- Questionário:}

1. Qual sua idade?

a) 18 a 25 anos

b) 26 a 35 anos

c) 36 a 45 anos

d) 46 a 55 anos

e) 56 a 65 anos

f) mais de 66 anos

2. Há quanto tempo está na atividade:
a) Menos de 5 anos
b) Entre 6 e 10 anos
c) Entre 11 e 15 anos
d) Entre 16 e 20 anos
e) Mais de 20 anos.

3. Alfabetização do respondente:
a) Não sabe ler nem escrever
b) Sabe ler/escrever sem grau de ensino
c) Ensino primário completo
d) Ensino secundário
e) Ensino médio/profissional
f) Ensino superior incompleto
g) Ensino superior completo

4. Infraestruturas disponíveis na habitação:
a) Água encanada
b) Eletricidade
c) Fossa sanitária
d) Banheiro 
e) Nenhuma

Outra:

5. É proprietário da parcela de terra onde produz?

a) Sim

b) Não

c) Outro membro do Agregado Familiar

6. Se é proprietário, como adquiriu?

a) Herança

b) Compra

c) Doação

Outra:

7. Indique que tipo de dificuldades enfrentadas:
a) Falta de apoio financeiro
b) Reduzido número de trabalhadores
c) Distância dos mercados e feiras
d) Falta de compradores
e) Falta de água
f) Avarias nas máquinas
g) Elevado custo da produção

8. Possui veículo próprio? Se sim, qual o ano de fabricação?
a) $\operatorname{sim}$
b) não
( ) $<1990$
( ) 1990 a 1995
( ) 1995 a 2000
( ) 2000 a 2005
( ) 2005a 2010 
( ) $>2011$

9. Quais eletrodomésticos/eletrônicos possui?

a) liquidificador

b) batedeira

C) microondas

d) geladeira

e) televisão

f) computador

g) dvd/vídeo-cassete

h) aparelho de som

i) notebook

j) celular

k) máquina de lavar roupas

10. Mão de obra utilizada na propriedade:
a) diarista
b) permanente

11. Onde reside?

a) Zona rural

b) Zona urbana

11.1. Se mora na cidade, qual o motivo?
a) Conforto
b) Filhos na escola
c) Facilidade para negociação
d) Facilidade de acesso a serviços e produtos

12. Quais os tipos de equipamentos usados na atividade?
a) Trator 

b) Ordenhadeira
c) tração animal (carroça)
d) botijão criogênico de sêmen

13. Quais as expectativas para produção de leite nos próximos 10 anos?
a) Manter
b) Aumentar
c) Diminuir
d) Parar

14. Qual a participação da família na atividade?
a) Pais
b) Filhos
c) Irmãos
d) Genros
e) Netos

15. Você esta satisfeito com o que faz?
a) $\mathrm{Sim}$
b) Não

16. Qual a origem de sua renda?
a) Somente produção de leite
b) Trabalha para terceiros
c) Exerce outra profissão
d) Aposentado

17. Você se vê em outra atividade produtiva?
a) $\operatorname{sim}$
b)não

( ) gado de corte 
( )agricultura

( )eucalipto

( )outra:

Agradecemos a sua disponibilidade para responder às questões. 